\title{
An Explanation for the Paradox Phenomenon in Taiwan's Bank Performances
}

\author{
Ming-Chung Chang ${ }^{1}$ \\ ${ }^{1}$ Department of Banking and Finance, Kainan University, Taiwan \\ Correspondence: Ming-Chung Chang, Department of Banking and Finance, Kainan University, No. 1 Kainan Rd., \\ Luchu, Taoyuan County 33857, Taiwan. Tel: 886-3-341-2500 x 6212. E-mail: changmc@mail.knu.edu.tw
}

Received: October 25, 2013

Accepted: November 13, $2013 \quad$ Online Published: January 10, 2014

doi:10.5430/ijfr.v5n1p21

URL: http://dx.doi.org/10.5430/ijfr.v5n1p21

\begin{abstract}
A traditional DEA (data envelopment analysis) model is useful for estimating the best performances for a successful and a more efficiency DMU (decision-making unit). This study uses a traditional DEA model to estimate the efficiency score of bank $\mathrm{z}$ in Taiwan and get a good efficiency score based on the 2006 data, however the bank $\mathrm{z}$ was taken over by the government in early 2007. In illustrating this paradox phenomenon, the study reconsiders the tradition DEA model by contributing a worst-practice frontier under a traditional DEA model. Findings: the bank $\mathrm{z}$ is located on the intersection of the worst-practice frontier and the traditional DEA model frontier. This study provides a critical determinant of a bank's failure that a bank has a location such as the bank $\mathrm{z}$.
\end{abstract}

Keywords: performance, efficiency, worst-practice frontier, bank's failure

\section{Introduction}

Measuring the efficiency of a decision making unit (DMU) is one of the major objectives of data envelopment analysis (DEA). Farrell (1957) builds a DEA methodology to estimate the ratio efficiency of a DMU through some specific mathematical programming models. Following Charnes et al. (1978) and Banker et al. (1984), the operations research and management science (OR/MS) researchers, economists, and experts apply the DEA methodology into their respective disciplines (Førsund and Sarafoglou, 2002, 2005). DEA can estimate the relative efficiency of bank without assuming a prior production function (Chebat et al., 1994), and provides a single efficiency score for each estimated bank based on multiple input and/or multiple output variables (Bauer et al., 1998).

In the DEA framework, excesses in inputs and shortfalls in outputs are called as slacks. Charnes et al. (1985) create an additive DEA model in which the slacks are used to calculate the efficiency value of DMU. The literature that attempts to define inefficiency based on the slacks includes Russell (1985), Pastor (1996), Lovell and Pastor (1995), Torgersen et al. (1996), Cooper and Tone (1997), and Sueyoshi and Goto (2011). Meanwhile, some studies turn the ratio efficiency and the slacks into a scalar measure (Tone, 1993).

Harris and Ogbonna (2001) use efficiency and effectiveness to be a criterion for estimating the DMU's performance. All DEA papers above are to indentify the DMU performances in the most favorable scenario in which the best efficient DMU construct a best-practice frontier as "best-practice frontier" DEA, i.e., BPF-DEA or call as the traditional frontier (Liu and Chen, 2009). The main contribution in the paper of Liu and Chen (2009) is to define the bad performances such as bankrupt firms in the most unfavorable scenario in which the worst efficient DMUs construct a worst-practice frontier as "worst-practice frontier" DEA, i.e., WPF-DEA. The journal papers basing on the DEA approaches to estimate the performance in the worst efficiency only include Paradi et al. (2004) and Liu and Chen (2009). The past literature has a lack of the discussion in the issue of WPF-DEA, but this study can provide a theoretical example and an empirical example to illustrate the importance of the issue of WPF-DEA. Table 1 provides a theoretical example comes. 
Table 1. A theoretical example

\begin{tabular}{ccccccccccc}
\hline \multirow{2}{*}{ Index } & \multirow{2}{*}{ Notation } & \multicolumn{10}{c}{ DMU } \\
\cline { 3 - 11 }$y$ & $A$ & $B$ & $C$ & $D$ & $E$ & $F$ & $G$ & $H$ \\
\hline Input 1 & $x_{1}$ & 4 & 7 & 8 & 4 & 1 & 4 & 6 & 3 \\
Input 2 & $x_{2}$ & 3 & 3 & 1 & 2 & 5 & 6 & 3 & 5 \\
Output & $y$ & 1 & 1 & 1 & 1 & 1 & 1 & 1 & 1 \\
\hline
\end{tabular}

Source: Liu and Chen (2009)

Figure 1 includes the locations of all DMUs. DMUs $C, D$, and $E$ are located on the best-practice frontier. In the BPF-DEA model, they are evaluated as efficient DMUs, and the other DMUs, i.e., $A, B, F$, $G$, and $H$, are less efficient DMUs which are far from the best-practice frontier. In the WPF-DEA model, DMUs $B, C$, and $F$ are estimated as the worst efficient DMUs which are located on the worst-practice frontier. The other DMUs, i.e., $A, D$, $E, G$, and $H$, are far from the worst-practice frontier, thus they are more efficient in comparison with the worst efficient DMUs.

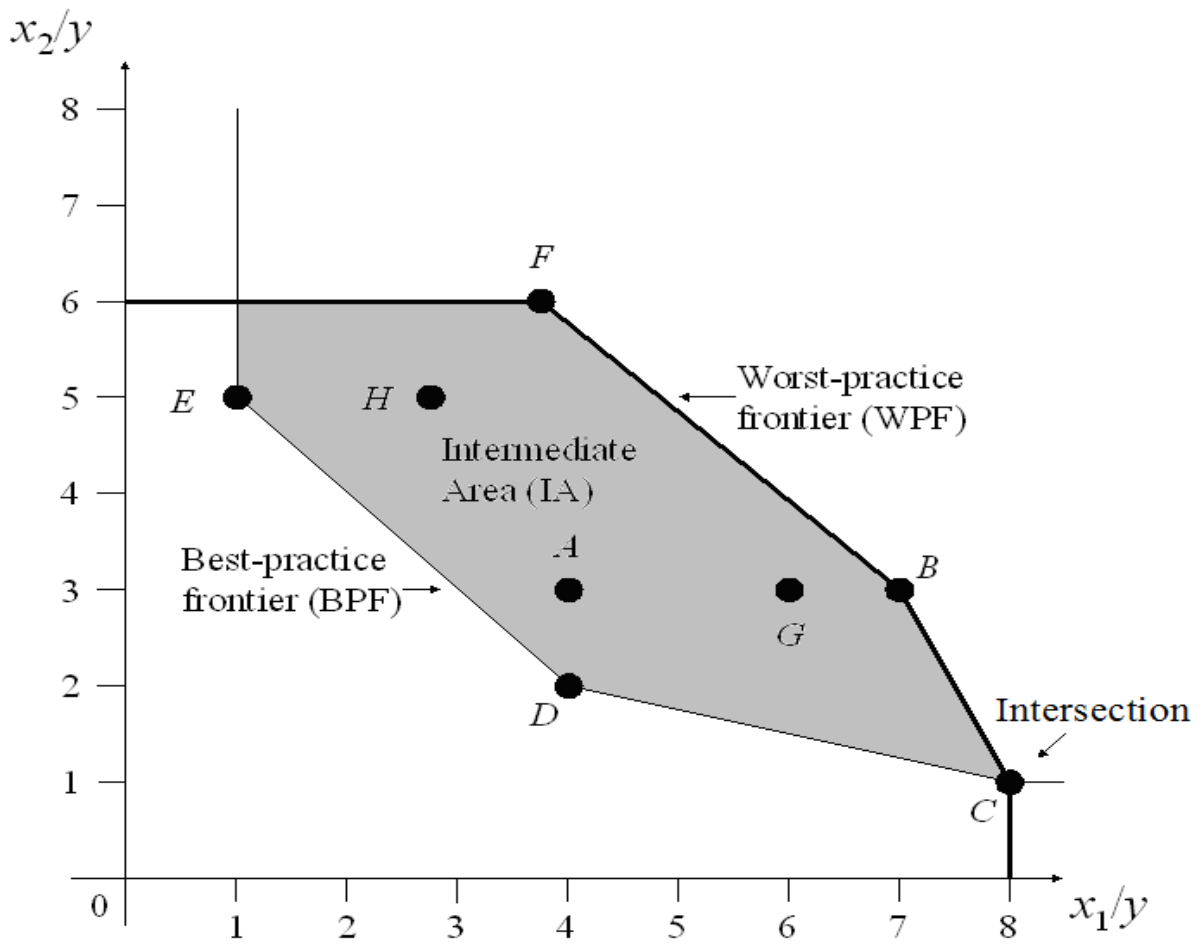

Figure 1. The best-practice frontier and the worst-practice frontier

In Figure 1, DMU $C$ is not only located on the best-practice frontier but also on the worst-practice frontier. Hence, we wonder whether DMU $C$ is an efficient DMU or the worst efficient DMU.

To answer this question, we use a local bank in Taiwan as example. Bank $z$ in Taiwan has a good performance in 2006 (as viewable in Table 5); however, this bank was taken over by the government in early 2007 since the bank suffered from a bank-run. Based on this situation, bank $z$ is not only located on the best-practice frontier but also on the worst-practice frontier such as DMU $C$ in Figure 1. Many past studies have concluded that the bank failure has been related to the profit performance of the banks (Akhigbe and Madura, 2001; Cannella et al., 1995; Chen, 1999; Miller, 1996; Thomson, 1991), but there are only two studies investigate the relationship between efficiency and bank failure (Siems, 1992; Luo, 2003). Siems (1992) suggests that profitability efficiency or management quality is a critical determinant of a bank's failure. Luo (2003) finds that the overall technical efficiency of the profitability performance can predict the likelihood of bank's failure. The purpose of our study is to suggest another viewpoint of estimating the likelihood of bank's failure by applying the WPF-DEA model.

The remaining structure of this study has the following structure. Section 2 describes the traditional DEA model provided by Banker et al. (1984) called as BCC model. On the other hand, the WPF-BCC model is also provided. 
Section 3 presents the data set and the variables utilized. Section 4 discusses the results of the BCC model and the WPF-BCC model. Section 5 concludes with a summary of the empirical results.

\section{Methodology}

The traditional DEA model such as BCC model provided by Banker et al. (1984) is a linear programming model that formulates the best-practice frontier which consists of efficient DMU. The efficiency score reflects the ability of DMU to generate the maximum outputs under a given level of inputs. On the contrary, a worst efficiency score for a DMU generates the minimum outputs under a given level of inputs.

\subsection{BCC Model}

$\mathrm{DMU}_{i}$ stands an evaluated entity which efforts to create a maximum output under a given level of inputs. The efficiency score of each $\mathrm{DMU}_{i}\left(\theta_{i}\right)$ metric comes from the ratio of all outputs over all inputs. BCC model proposed by Banker et al. (1984) is as follows:

$$
\begin{gathered}
\operatorname{Max} \theta_{i}=\frac{\sum_{t=1}^{T} u_{t} y_{i}^{t}-u_{0}}{\sum_{s=1}^{S} v_{s} x_{i}^{s}} \\
\text { s.t. } \frac{\sum_{t=1}^{T} u_{t} y_{j}^{t}-u_{0}}{\sum_{s=1}^{S} v_{s} x_{j}^{s}} \leq 1, j=1, \ldots, N, \\
v_{s}, u_{t} \geq 0, s=1, \ldots, S, t=1, \ldots, T, \\
u_{0} \in R .
\end{gathered}
$$

The variables $x_{j}^{s}, y_{j}^{t}$ stand for the $s$ th input and the $t$ th output that are used and produced by the $j$ th DMU. The total DMU number, total input number, and total output number are $N, S$, and $T$, respectively. The variables $v_{s}$ and $u_{t}$ are the weights of $s$ th input and $t$ th output, respectively. The variable $u_{0}$ is an interception term that $u_{0}>0, u_{0}=0$, and $u_{0}$ $<0$ represent that the efficiency frontier is the decreasing returns to scale (DRS), constant returns to scale (CRS), and increasing returns to scale (IRS), respectively. The sign of $u_{0}$ captures the main character of BCC model that its efficient frontier belongs to variable returns to scale (VRS).

The number of optimal solution combination on the weights of input and output $\left(v_{s}^{*}, u_{t}^{*}\right)$ in Equation (1) is infinite.

For obtaining the only one optimal solution in BCC model, we impose the constraint $\sum_{s=1}^{S} v_{s} x_{i}^{s}=1$ in Equation

(1), which provides:

$$
\begin{gathered}
\operatorname{Max} \theta_{i}=\sum_{t=1}^{T} u_{t} y_{i}^{t}-u_{0} \\
\text { s.t. } \sum_{s=1}^{S} v_{s} x_{i}^{s}=1 \\
\sum_{s=1}^{S} v_{s} x_{j}^{s}-\sum_{t=1}^{T} u_{t} y_{j}^{t}+u_{0} \geq 0, j=1, \ldots, N, \\
v_{s}, u_{t} \geq 0, s=1, \ldots, S, t=1, \ldots, T, \\
u_{0} \in R .
\end{gathered}
$$

The duality solution of BCC model is used to measure the efficiency score $\theta_{i}$ for $\mathrm{DMU}_{i}$ is shown as:

$$
\begin{gathered}
1 / \theta_{i}=\operatorname{Min} \phi_{i} \\
\text { s.t. } \sum_{j=1}^{N} \lambda_{j} x_{j}^{s}-\phi_{i} x_{i}^{s} \geq 0, s=1, \ldots, S, \\
\sum_{j=1}^{N} \lambda_{j} y_{j}^{t}-y_{i}^{t} \leq 0, t=1, \ldots, T, \\
\\
\sum_{j=1}^{N} \lambda_{j}=1, \text { for } \forall \lambda_{j} \geq 0 .
\end{gathered}
$$


The variable $\phi_{i}$ is an inverse efficiency score of $\mathrm{DMU}_{i}$; in other words, the efficiency score $\theta_{i}$ of $\mathrm{DMU}_{i}$ is $1 / \phi_{i}$.

\subsection{WPF-BCC Model}

The purpose of the WPF-BCC model is different with BCC model since the former is to examine how bad a DUM's performance could possibility be in a worst scenario. Hence, the objective function in WPF-BCC model is to minimize the efficiency score of DMU. In WPF-BCC model, the DMUs with the worst efficiency are located on the worst-practice frontier and the DMUs with more efficient are far from the worst-practice frontier. For establishing a worst-practice frontier, we formulate WPF-BCC model below:

$$
\begin{gathered}
\operatorname{Min} h_{i}=\frac{\sum_{t=1}^{T} u_{t} y_{i}^{t}-u_{0}}{\sum_{s=1}^{S} v_{s} x_{i}^{s}} \\
\text { s.t. } \frac{\sum_{t=1}^{T} u_{t} y_{j}^{t}-u_{0}}{\sum_{s=1}^{S} v_{s} x_{j}^{s}} \geq 1, j=1, \ldots, N, \\
v_{s}, u_{t} \geq 0, s=1, \ldots, S, t=1, \ldots, T, \\
u_{0} \in R .
\end{gathered}
$$

The two main difference between BCC model and WPF-BCC model are (i) WPF-BCC model is to minimize the objective function; (ii) the constraint for the ratio scales of the weighted sum of the outputs to that of the inputs in WPF-BCC model should larger than or equal to 1.

We translate the fractional programming in Equation (4) into the following linear programming as follows:

$$
\begin{gathered}
\operatorname{Min} h_{i}=\sum_{t=1}^{T} u_{t} y_{i}^{t}-u_{0} \\
\text { s.t. } \sum_{s=1}^{S} v_{s} x_{i}^{s}=1 \\
\sum_{s=1}^{S} v_{s} x_{j}^{s}-\sum_{t=1}^{T} u_{t} y_{j}^{t}+u_{0} \leq 0, j=1, \ldots, N, \\
v_{s}, u_{t} \geq 0, s=1, \ldots, S, t=1, \ldots, T, \\
u_{0} \in R .
\end{gathered}
$$

The duality solution of WPF-BCC model is used to measure the efficiency score $\theta_{i}$ for $\mathrm{DMU}_{i}$ is shown as:

$$
\begin{gathered}
1 / h_{i}=\operatorname{Max} \varphi_{i} \\
\text { s.t. } \quad \sum_{j=1}^{N} \lambda_{j} x_{j}^{s}-\varphi_{i} x_{i}^{s} \geq 0, s=1, \ldots, S, \\
\sum_{j=1}^{N} \lambda_{j} y_{j}^{t}-y_{i}^{t} \leq 0, t=1, \ldots, T, \\
\sum_{j=1}^{N} \lambda_{j}=1, \text { for } \forall \lambda_{j} \geq 0 .
\end{gathered}
$$

In the WPF-BCC model, the optimal efficiency score $\varphi_{i}{ }^{*}$ of DMUi is not less than 1 . And the more efficient the DMU is, the higher the efficiency score will be. $\phi_{i}^{*}=1$ represents that the DMU $i$ is the worst efficient.

\subsection{Variables and Data}

This study follows the article of Kao and Liu (2004) to consider three output factors - total loans, interest income, and non-interest income; and three input factors - total deposits, interest expenses, and non-interest expenses. We referred to the 2006 data which includes 28 commercial banks in Taiwan. All variable data are obtained from Taiwan Economic Journal Co. Ltd and were showed in Table 2. 
Table 2. Data set

\begin{tabular}{|c|c|c|c|c|c|c|}
\hline Bank & $\begin{array}{l}\text { Total } \\
\text { Loans }\end{array}$ & $\begin{array}{l}\text { Interest } \\
\text { Income }\end{array}$ & $\begin{array}{l}\text { Non-interest } \\
\text { Income }\end{array}$ & $\begin{array}{c}\text { Total } \\
\text { Deposits }\end{array}$ & $\begin{array}{c}\text { Interest } \\
\text { Expenses }\end{array}$ & $\begin{array}{l}\text { Non-interest } \\
\text { Expenses }\end{array}$ \\
\hline 1 & 9949004 & 247094 & 57537 & 1021949 & 129793 & 126519 \\
\hline 2 & 10733523 & 299098 & 46383 & 1218813 & 165739 & 204737 \\
\hline 3 & 11376596 & 317947 & 47193 & 1281473 & 172087 & 242758 \\
\hline 4 & 10095851 & 293450 & 72272 & 1054245 & 190943 & 150572 \\
\hline 5 & 1527592 & 30928 & 6437 & 165924 & 14379 & 28008 \\
\hline 6 & 2204190 & 55127 & 6422 & 239796 & 21830 & 65743 \\
\hline 7 & 9666212 & 366101 & 156522 & 1127463 & 152548 & 998044 \\
\hline 8 & 7646072 & 267069 & 114931 & 882230 & 104155 & 321723 \\
\hline 9 & 6913189 & 272629 & 172493 & 775743 & 149105 & 379949 \\
\hline 10 & 1519886 & 70254 & 7961 & 145462 & 24160 & 100526 \\
\hline 11 & 8547871 & 181819 & 101324 & 794951 & 100612 & 213067 \\
\hline 12 & 1201077 & 26293 & 8112 & 118756 & 13716 & 24931 \\
\hline 13 & 1794348 & 99880 & 15788 & 191087 & 28109 & 141984 \\
\hline 14 & 4117899 & 140932 & 170728 & 755549 & 93019 & 299625 \\
\hline 15 & 4818838 & 129076 & 106027 & 518957 & 67726 & 328514 \\
\hline 16 & 2692910 & 70302 & 20792 & 267418 & 31813 & 94650 \\
\hline 17 & 6291581 & 273542 & 557203 & 620027 & 90728 & 1434310 \\
\hline 18 & 2616682 & 75107 & 23138 & 250095 & 40195 & 132705 \\
\hline 19 & 2717238 & 86090 & 16669 & 252352 & 36675 & 223148 \\
\hline 20 & 2444741 & 73371 & 59035 & 222111 & 34419 & 137765 \\
\hline 21 & 895137 & 43286 & 12741 & 106456 & 18329 & 64969 \\
\hline 22 & 2508675 & 76992 & 17204 & 286922 & 29008 & 111257 \\
\hline 23 & 2040497 & 46270 & 4646 & 212951 & 21744 & 38255 \\
\hline 24 & 2190725 & 73661 & 48895 & 200233 & 28390 & 197716 \\
\hline 25 & 821664 & 17087 & 2245 & 85686 & 7318 & 15615 \\
\hline 26 & 18270859 & 357268 & 69672 & 1822979 & 228439 & 207890 \\
\hline 27 & 1690972 & 36878 & 16112 & 156530 & 18221 & 41848 \\
\hline 28 & 2758271 & 88112 & 35233 & 354848 & 43122 & 56825 \\
\hline
\end{tabular}

1. Unit: One hundred thousand New Taiwan dollars

2. Data sources: Taiwan Economic Journal Co. Ltd (http://www.finasia.biz/ensite/Default.aspx?TabId=121)

The descriptive statistics for six variables are shown in Table 3.

Table 3. Descriptive statistics table

\begin{tabular}{lrrrr}
\hline \multicolumn{1}{c}{ Variables } & Average & \multicolumn{1}{c}{ Max } & \multicolumn{1}{c}{ Min } & \multicolumn{1}{c}{$\begin{array}{c}\text { Standard } \\
\text { deviation }\end{array}$} \\
\hline Outputs & & & & \\
Total loans & 5001861 & 18270859 & 821664 & 4304131 \\
Interest income & 146988 & 366101 & 17087 & 114221 \\
Non-interest income & 70490 & 557203 & 2245 & 108321 \\
Inputs & & & & \\
Total deposits & 540393 & 1822979 & 85686 & 458606 \\
Interest expenses & 73440 & 228439 & 7318 & 64293 \\
Non-interest expenses & 227988 & 1434310 & 15615 & 302175 \\
\hline
\end{tabular}


The standard deviation of the total loans for 28 commercial banks in Taiwan is larger than that of the total deposits. This result implies that there is a large difference between the size of total loans and the size of total deposits among the samples. The standard deviation of the interest expense is small. This result implies that the bank's cost in interest expenses is seriously controlled.

\section{Empirical Results}

This section uses the BCC model and WPF-BCC model to analyze the real data of the 28 commercial banks in Taiwan and then to illustrate a phenomenon that bank $z$ in Taiwan has a good efficiency score in 2006, but the bank $z$ was taken over by the government in the early 2007 .

We firstly calculate the efficiency score for each DMU in Figure 1 and describe their locations. The result appears in Table 4.

Table 4. Take Figure 1 as an example to describe the DMUs' locations

\begin{tabular}{ccclc}
\hline DMU & BCC model & WPF-BCC model & \multicolumn{1}{c}{ Location } & Notation \\
\hline$A$ & 0.857 & 1.429 & In an intermediate area & IA \\
$B$ & 0.632 & 1 & On WPF & WPF \\
$C$ & 1 & 1 & On an intersection of BPF and WPF & Intersection \\
$D$ & 1 & 1.667 & On BPF & BPF \\
$E$ & 1 & 1.2 & On BPF & BPF \\
$F$ & 0.6 & 1 & On WPF & WPF \\
$G$ & 0.667 & 1.111 & In an intermediate area & IA \\
$H$ & 0.75 & 1.2 & In an intermediate area & IA \\
\hline
\end{tabular}

We distinguish the location for each DMU in Table 4 as follows:

(i) DMUs $D$ and $E$ with the efficiency score $=1$ in BCC model and the efficiency score $>1$ in WPF-BCC model are located on the best-practice frontier (BPF);

(ii) DMUs $B$ and $F$ with the efficiency score $<1$ in BCC model and the efficiency score $=1$ in WPF-BCC model are located on the worst-practice frontier (WPF);

(iii) DMUs $A, G$, and $H$ with the efficiency score $<1$ in BCC model and the efficiency score $>1$ in WPF-BCC model are located in the intermediate area (IA);

(iv) DMU $C$ with the efficiency score $=1$ in BCC model and the efficiency score $=1$ in WPF-BCC model are located on the intersection of BPF and WPF.

We secondly use both BCC model and WPF-BCC model to investigate the reason as to why bank $z$ has a good efficiency score in BCC model, but was taken over by the government. Bank $z$ is bank 10 in the sample. Since bank $z$ has an efficiency score $=1$ in BCC model and an efficiency score $=1$ in WPF-BCC model, its location is on the intersection of BPF and WFP. Among 28 samples of commercial bank, bank $z$ was later taken over by the government in early 2007. Finally, there are two main conclusions in this study: (i) a real more efficient DMU should have an efficiency score in BCC model as 1, and an efficiency score in WPF-BCC model to be larger than 1 such as banks 1, 8, 11, 20,24, 27, and 28; (ii) a DMU is a potentially failed firm if its efficiency scores in BCC model and in WPF-BCC model are equal to 1 such as the bank 10, i.e., bank $z$. This study provides another way to predict the likelihood of bank failures. Our way is different with those provided by Siems (1992) and Luo (2003). 
Table 5. The locations for 28 commercial banks in Taiwan

\begin{tabular}{cccccccc}
\hline Bank & BCC model & $\begin{array}{c}\text { WPF-BCC } \\
\text { model }\end{array}$ & Location & Bank & BCC model & $\begin{array}{c}\text { WPF-BCC } \\
\text { model }\end{array}$ & Location \\
\hline 1 & 1 & 1.090 & BPF & 15 & 0.861 & 1.008 & IA \\
2 & 0.923 & 1 & WPF & 16 & 0.956 & 1.117 & IA \\
3 & 0.91 & 1 & WPF & 17 & 1 & 1 & Intersection \\
4 & 1 & 1 & Intersection & 18 & 0.958 & 1 & WPF \\
5 & 1 & 1 & Intersection & 19 & 0.983 & 1 & WPF \\
6 & 0.982 & 1 & WPF & 20 & 1 & 1.206 & BPF \\
7 & 0.833 & 1 & WPF & 21 & 0.915 & 1 & WPF \\
8 & 1 & 1.135 & BPF & 22 & 0.939 & 1 & WPF \\
9 & 1 & 1 & Intersection & 23 & 0.984 & 1 & WPF \\
$10(z)$ & 1 & 1 & Intersection & 24 & 1 & 1.132 & BPF \\
11 & 1 & 1.132 & BPF & 25 & 1 & 1 & Intersection \\
12 & 0.977 & 1.094 & IA & 26 & 1 & 1 & Intersection \\
13 & 1 & 1 & Intersection & 27 & 1 & 1.157 & BPF \\
14 & 1 & 1 & Intersection & 28 & 1 & 1.006 & BPF \\
\hline
\end{tabular}

\section{Conclusion}

Researchers use a traditional DEA model to calculate the efficiency score of DMU and to estimate its efficiency level. The study here uses a BCC model to calculate the efficiency score of bank $z$ in Taiwan and get its efficiency score as 1 in 2006. The result of the efficiency score in the BCC model shows that bank $z$ has a good performance, but the bank $z$ was taken over by government in early 2007. To explain this paradox phenomenon, we use the concept of the worst-practice frontier proposed by Liu and Chen (2009) to establish the WPF-BCC model to find the DMUs with the worst performance.

In the WPF-BCC model, the worst efficiency is not less than 1. The unit with a higher efficiency score is a more efficient DMU; on the contrary, the unit with an efficiency score being 1 is a worst efficient. The calculation result of the efficiency scores using both BCC model and WPF-BCC model shows that the efficiency scores of the bank $z$ in BCC model and WPF-BCC model are 1. This result illustrates that bank $z$ is located not only on the best-practice frontier but also on the worst-practice frontier; in other words, bank $z$ lies on the intersection of the best-practice frontier and the worst-practice frontier. Hence, we suggest that a bank has a likelihood of bank failure when the location of a bank is the same as bank $z$. The main contribution of this study is to provide a new way for predicting the likelihood of bank failures. Our way is different with those provided by Siems (1992) and Luo (2003).

This study creates a combination of BCC model and WPF-BCC model for investigating a potentially failed firm such as bank $z$ in Taiwan. The combination of BCC model and WPF-BCC model provides a new viewpoint to reconsider and re-examine an efficient DMU in the traditional DEA model. The concept of this study can also apply to examine the risk-taking industries for reducing investment risks. The concept of worst-practice frontier is also extended to other the traditional DEA model.

\section{Acknowledgements}

The author thanks an editorial board member and an anonymous referee for their valuable comments. Financial support from Taiwan's National Science Council is gratefully acknowledged (NSC 102-2410-H-424 -020).

\section{References}

Akhigbe, A., \& Madura, J. (2001). Why do contagion effects vary among bank failures? Journal of Banking \& Finance, 25, 657-680. http://dx.doi.org/10.1016/S0378-4266(00)00092-3

Banker, R.D., Charnes, A., \& Cooper, W.W. (1984). Some models for estimating technical and scale inefficiencies in data envelopment analysis. Management Science, 30, 1078-1092. http://dx.doi.org/10.1287/mnsc.30.9.1078

Bauer, P., Berger, A., Ferrier, G., \& Humphrey, D. (1998). Consistency conditions for regulatory analysis of financial institutions: A comparison of frontier efficiency methods. Journal of Economics and Business, 50, 85-114. http://dx.doi.org/10.1016/S0148-6195(97)00072-6 
Cannella, A., Fraser, D., \& Lee, S. (1995). Firm failure and managerial labor markets: Evidence from texas banking. Journal of Financial Economics, 38, 185-210. http://dx.doi.org/10.1016/0304-405X(94)00810-N

Charnes, A., Cooper, W.W., \& Rhodes, E. (1978). Measuring the efficiency of decision making units. European Journal of Operational Research, 2, 429-444. http://dx.doi.org/10.1016/0377-2217(78)90138-8

Charnes, A., Cooper, W.W., Golany, B., Seiford, L., \& Stutz, J. (1985). Foundation of data envelopment analysis and Pareto-Koopmans empirical production functions. Journal of Econometrics, 30, 91-107. http://dx.doi.org/10.1016/0304-4076(85)90133-2

Chebat, J., Ierre, F., Arnon, K., \& Sholomom, T. (1994). Strategic auditing of human and financial resource allocation in marketing: An empirical study using data envelopment analysis. Journal of Business Research, 31, 197-208. http://dx.doi.org/10.1016/0148-2963(94)90083-3

Chen, Y. (1999). Banking panics: The role of the first-come, first-served rule and information externalities. Journal of Political Economy, 107, 946-968. http://dx.doi.org/10.1086/250086

Cooper, W.W., \& Tone, K. (1997). Measures of inefficiency in data envelopment analysis and stochastic frontier $\begin{array}{llll}\text { estimation. European Journal of Operational Research, 99, } & \text { 72-88. }\end{array}$ http://dx.doi.org/10.1016/S0377-2217(96)00384-0

Farrell, M.J. (1957). The measurement of productive efficiency. Journal of the Royal Statistical Society, Series A (General), 120, 253-281. http://dx.doi.org/10.2307/2343100

Førsund, F.R., \& Sarafoglou, N. (2002). On the origins of data envelopment analysis. Journal of Productivity Analysis, 17, 23-40. http://dx.doi.org/10.1023/A:1013519902012

Førsund, F.R., \& Sarafoglou, N. (2005). The tale of two research communities: The diffusion of research on productive efficiency. International Journal of Production Economics, 98, 17-40. http://dx.doi.org/10.1016/j.ijpe.2004.09.007

Harris, L.C., \& Ogbonna, E. (2001). Strategic human resource management, market orientation, and organizational performance. Journal of Business Research, 51, 157-166. http://dx.doi.org/10.1016/S0148-2963(99)00057-0

Kao, C., \& Liu, S. T. (2004). Predicting bank performance with financial forecasts: A case of Taiwan commercial banks. Journal of Banking \& Finance, 28, 2353-2368. http://dx.doi.org/10.1016/j.jbankfin.2003.09.008

Liu, F.H.F., \& Chen, C.L. (2009). The worst-practice DEA model with slack-based measurement. Computers \& Industrial Engineering, 57, 496-505. http://dx.doi.org/10.1016/j.cie.2007.12.021

Lovell, C.A.K., \& Pastor, J.T. (1995). Units invariant and translation invariant DEA models. Operations Research Letters, 18, 147-151. http://dx.doi.org/10.1016/0167-6377(95)00044-5

Luo, X. (2003). Evaluating the profitability and marketability efficiency of large banks: An application of data envelopment analysis. Journal of Business Research, 56, 627-635. http://dx.doi.org/10.1016/S0148-2963(01)00293-4

Miller, W. (1996). Bank failures in Connecticut: A study and comparison of performance. American Business Review, 14, 25-37.

Paradi, J.C., Asmild, M., \& Simak, P.C. (2004). Using DEA and worst practice DEA in credit risk evaluation. Journal of Productivity Analysis, 21, 153-165. http://dx.doi.org/10.1023/B:PROD.0000016870.47060.0b

Pastor, J.T. (1996). Translation invariance in DEA: A generalization. Annals of Operations Research, 66, 93-102.

Russell, R.R. (1985). Measures of technical efficiency. Journal of Economic Theory, 35, 109-126. http://dx.doi.org/10.1016/0022-0531(85)90064-X

Siems, T.F. (1992). Quantifying management's role in bank survival. Economic Review, January, 29-41.

Sueyoshi, T., \& Goto, M. (2011). Methodological comparison between two unified (operational and environmental) efficiency measurements for environmental assessment. European Journal of Operational Research, 210, 684-693. http://dx.doi.org/10.1016/j.ejor.2010.10.030

Thomson, J.B. (1991). Predicting bank failures in the 1980s. Economic Review, 27, 9-20.

Tone, K. (1993). An $\varepsilon$-free DEA and a new measure of efficiency. Journal of the Operations Research Society of Japan, 36, 167-174.

Torgersen, A.M., Førsund, F.R., \& Kittelsen, S.A.C. (1996). Slack-adjusted efficiency measures and ranking of efficient units. Journal of Productivity Analysis, 7, 379-398. http://dx.doi.org/10.1007/BF00162048 